\title{
Chemical Heritage Foundation Fellowships
}

T he Chemical Heritage Foundation, an independent historical research center, library, and museum in Philadelphia, Pennsylvania, USA, is now accepting applications for long-term and shortterm fellowships in residence at CHF's Beckman Center for the History of Chemistry for the academic year 2010-2011. These fellowships are for scholars working in some area of the history and social studies of alchemical, chymical, chemical, and related sciences, technologies, crafts, or industries in all chronological and geographical areas. An overview of the kinds of research CHF supports, including work being done by its current and past fellows, can be found online at <www.chemheritage.org/ research/research.html>.

The research collections at $\mathrm{CHF}$, where the chosen fellows will be in residence throughout their fellowship period, range from the fifteenth century to the present and include approximately 10000 rare book volumes,

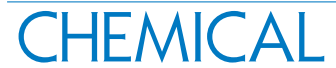
HERITAGE

FOUNDATION significant archival holdings, thousands of images, and a large artifact and fine arts collection, supported by over 100000 reference volumes, monographs, and journals. Within the collections there are many areas of special strength, including alchemy, mining and metallurgy, dyeing and bleaching, balneology, gunpowder and pyrotechnics, gas lighting, books of secrets, inorganic and organic chemistry, biochemistry, food chemistry, and pharmaceuticals. Recipients of all fellowships are expected to participate in and make a contribution to CHF's intellectual life. CHF is also an active member in the Philadelphia Area Center for the History of Science <www.pachs.net>.

CHF currently has nine staff members with Ph.Ds. and targets to have at least an equivalent number of visiting scholars in residence at any one time to have an active and thriving scholarly community. Last year CHF gave four long-term postdoctoral, three longterm dissertation, and nine short-term fellowships.

The deadline for applications is 15 February 2010. Apply online at <www.chemheritage.org/research/ research-nav4.html>. Fellows will be selected by an external peer-review selection committee and awardees should be notified in April 2010.

\section{New Leadership at IOCD}

A lain Krief has been named executive director of the International Organization for Chemicals Science in Development, replacing Robert Maybury, whose more than two decades of leadership enabled the IOCD to become a highly diversified and recognized organization throughout the world. Krief, previously director of the Laboratory of Organic Chemistry at the University Notre Dame de la Paix at Namur in Belgium is widely known in scientific and industrial circles. He is a member of numerous scientific committees, an expert for scientific associations, and a member of editorial boards of scientific journals. Krief's international experience is extensive: Born in Africa, he studied in France, UK, and USA, and was a visiting professor several times at more than 15 universities worldwide.

IOCD was created in 1981 by Pierre Crabbé, a Belgian chemist working at UNESCO in Paris, with the objective of engaging scientists from developing countries in collaborative research with scientists from industrialized countries. After the sudden death of Crabbé in 1987, Maybury was appointed to continue and develop the work of its founder. Under Maybury, several additional working groups were created to round out IOCD's attention to the needs and limited resources of developing countries in the areas of environmental and analytical chemistry, medicinal chemistry, plant chemistry, biotic exploration, and natural products chemistry. For this, IOCD received generous funding from public and private donors. A great effort was made to transfer knowledge, through the project Books for Development and through the provision of grants to early-career scientists to enable them to participate in workshops and international scientific congresses. In recognition of his work, IOCD has named him honorary director.

IOCD's mission is to support collaboration in the chemical sciences to benefit the health, agricultural, and economic sectors of developing countries. The IOCD is an Associated Organization of IUPAC and has conducted several successful joint projects (e.g., on Standardization of Analytical Approaches and Analytical Capacity-Building in Africa (see Nov-Dec 2006 Cl, <www.iupac.org/publications/ci/2006/2806/ ud2.html>.

www.iocd.org

www.chemheritage.org 